\title{
Gait, physical function, and physical activity in three groups of home-dwelling older adults with different severity of cognitive impairment - a cross-sectional study
}

Kristin Taraldsen ${ }^{1,2,3^{*}}$, Jorunn L. Helbostad ${ }^{2}$, Turid Follestad ${ }^{4}$, Sverre Bergh ${ }^{5,6}$, Geir Selbæk ${ }^{6,7,8}$ and Ingvild Saltvedt ${ }^{2,9}$

\begin{abstract}
Background: The research on associations between gait, physical function, physical activity (PA), and cognitive function is growing. Still, clinical assessments of cognitive function and motor function is often kept separate. In this study, we aimed to look at a broad range of measures of gait, physical function, and PA in three groups of home-dwelling older adults with no or questionable dementia, mild dementia, and moderate/severe dementia.
\end{abstract}

Methods: This cross-sectional study included 100 home-dwelling older adults, recruited from an outpatient geriatric memory clinic. Severity of dementia was categorised using the clinical dementia rating scale (CDR), with no or questionable dementia (CDR score 0 and 0.5), mild dementia (CDR score 1) and moderate/severe dementia (CDR score 2 and 3). We used thigh worn accelerometers to measure daily PA, the Short Physical Performance Battery (SPPB) to measure physical function, and an electronic gait mat to evaluate gait characteristics. Associations between severity of dementia and measures of PA, physical function, and gait characteristics were assessed by linear regression.

Results: Participants' (mean age 78.9 (SD 6.7) years, 57\% women) average gait speed was $0.93 \mathrm{~m} / \mathrm{sec}$, and average upright time was $301 \mathrm{~min} /$ day. Statistically significant associations were found for the severity of dementia and gait speed ( $p=0.002$ ), step time ( $p=0.001$ ), physical function (SPPB, $p=0.007$ ), and PA (upright time, $p=0.031$ ), after adjusting for age. Overall, having no or questionable dementia was associated with faster gait speed (mean difference 0.163 ( $95 \%$ Cl: 0.053 to 0.273$)$ ), shorter step time (-0.043 (-0.082 to -0.005$)$ ), better SPPB score (1.7 (0.5 to 2.8)), and longer upright time (78.9 (18.9 to 139.0)), compared to those with mild dementia. Furthermore, having no or questionable dementia was also associated with faster gait speed and better SPPB scores, as compared to those with moderate to severe dementia. No evidence of any differences was found between the participants with the mild dementia versus the moderate to severe dementia.

Conclusions: After adjusting for age, we found that the no or questionable dementia group to be associated with better gait and physical function, and more PA, as compared with the two groups with mild or moderate/ severe dementia. Evaluation of gait, physical function, and PA can add clinically important information of everyday

\footnotetext{
*Correspondence: Kristin.Taraldsen@oslomet.no

${ }^{1}$ Department of Physiotherapy, Faculty of Health Sciences, Oslo

Metropolitan University (OsloMet), Oslo, Norway

Full list of author information is available at the end of the article
}

(C) The Author(s) 2021. Open Access This article is licensed under a Creative Commons Attribution 4.0 International License, which permits use, sharing, adaptation, distribution and reproduction in any medium or format, as long as you give appropriate credit to the original author(s) and the source, provide a link to the Creative Commons licence, and indicate if changes were made. The images or other third party material in this article are included in the article's Creative Commons licence, unless indicated otherwise in a credit line to the material. If material is not included in the article's Creative Commons licence and your intended use is not permitted by statutory regulation or exceeds the permitted use, you will need to obtain permission directly from the copyright holder. To view a copy of this licence, visit http://creativecommons.org/licenses/by/4.0/. The Creative Commons Public Domain Dedication waiver (http://creativeco mmons.org/publicdomain/zero/1.0/) applies to the data made available in this article, unless otherwise stated in a credit line to the data. 
functioning in memory clinics meeting geriatric patients, but investigations on how to use these results to guide interventions are still needed.

Keywords: Elderly, Physical activity, Accelerometers, Dementia

\section{Background}

It is well known that gait and physical function is affected among patients with advanced dementia. Slow gait speed may also precede decline in cognitive function in healthy older adults [1]. Furthermore, gait impairment in older persons is linked to cognitive decline, in particular executive function [2]. There is also evidence that the combination of slow gait and cognitive complaints may identify individuals at high risk for developing dementia [3-5]. In fact, regardless of the definition used, gait performance and cognitive dysfunction is suggested closely related, as poor gait performance has been shown to be present years before dementia was diagnosed [6]. It is suggested that research on the interrelationship between cognitive functioning and gait is important for understanding how the two are related and potentially help targeting interventions in order to prevent functional decline and improve quality of life at older age [7].

Level of Physical activity (PA) is associated with physical function at old age, and physical activity is suggested to be beneficial to maintain cognitive function [8]. For persons with established cognitive impairment, important benefits of PA, such as maintaining physical function and ability to perform everyday-life functions, have been demonstrated $[9,10]$. A recent publication from a longitudinal study also found an association between physical activity and slower cognitive decline among participants with both low and high concentrations of total tau, a brain protein used as a blood biomarker for Alzheimer's disease [11]. Objective measures of PA are however rarely included in assessment of persons with cognitive impairment, and how physically active these persons actually are, is not well described.

Based on the literature it is reason to believe that even persons with mild cognitive impairment (MCI) have alterations in gait characteristics [3] that will be increasing with the severity of dementia. Gait function and PA measures could potentially provide useful information when suspecting a cognitive impairment, but such measures are more rarely included in clinical evaluations. In this exploratory study, we aimed to examine gait, physical function, and PA, in three groups of different severity of cognitive impairment, in persons at the time of the first clinical work-up at a geriatric memory clinic.

\section{Methods}

\section{Study design and setting}

This is an observational, cross-sectional study performed at the Geriatric Memory Clinic at St Olavs University Hospital, Trondheim, Norway, where older patients with potential symptoms of cognitive impairment are referred from general practitioners. Participants were eligible for participation if they had agreed to take part in the Norwegian Register of Persons assessed for Cognitive Symptoms (NorCog) and were able to give their informed consent. The study was approved by the Norwegian Ethical Committee (2014/1689/REK sør-øst A).

\section{Participants}

Participants were included from February 2015 to April 2016. Consecutive inclusion at the outpatient clinic was performed until 100 participants were included. Inclusion criteria were being a participant in the NorCog register, living at home, living in the municipality of Trondheim, and being able to walk.

\section{Procedure}

The clinical assessment of the participants was performed in accordance with international and national guidelines [12] by use of assessments for the NorCog register completed by consultants and nurses employed at the memory clinic. Patients and caregivers were interviewed about symptoms and function, and all patients underwent clinical examination and cognitive testing.

Physical examination, lasting 15 to 30 minutes, was performed by a physiotherapist in a gait lab immediately after the standard cognitive work up. An activity monitor was fixed to the participants' thigh and was worn continuously for one week.

\section{Background information}

We collected information about body height and weight, age, gender, marital status, years of education, occupational status, living arrangements, whether people lived alone or not, and whether they received assistance from the municipality health care service.

Instrumental Activities of Daily Living (IADL) was assessed with the Lawton and Brody (1969) scale [13]. The scale comprises assessment of need of assistance in eight instrumental activities of daily living: using the phone, grocery shopping, preparing meals, housekeeping, laundering, using transportation, taking medications, 
and managing finances, and for each item the responders scored according to their highest functional level. A summary-score was calculated, ranging from 0 to 8 for women and 0 to 5 for men $[14,15]$, from low (dependent) to high (independent) function. Single missing items were given the score 0 . Grip strength (in $\mathrm{kg}$ ) on dominant side, was measured by use of a hand-held dynamometer (JAMAR) by using the best score out of three.

\section{Measurements of cognitive function}

The Clinical Dementia Rating scale (CDR) was used to rate the severity of dementia [16]. The medical doctor scored the CDR after completing a broader test battery of cognitive tests, and the scale represents how cognitive function affect aspects in their daily life. In the present study, we created three groups based on the CDR scores of 0 and 0.5 (no or questionable dementia), 1 (mild dementia), and 2 and 3 (moderate and severe dementia).

To have descriptive in-depth information about cognitive function we also included additional performancebased tests. The Norwegian version of the Mini Mental State Examination (MMSE) was used to describe global cognitive function [17]. The test is scored from 0 to 30 , with 30 as the best score. The Clock Drawing Test (CDT) [18] was used as a measure of visuospatial abilities and executive function, with test scores ranged from 0 (inability to make any reasonable attempt) to 5 (perfect clock) [19]. The Trail Making Test A and B (TMT-A and TMT-B) [20-22] were used to assess psychomotor speed, attention, and executive function. The time to complete TMT-A and TMT-B was registered (seconds), where long time reveal greater impairment. For participants able to start but not completing the tests within 300 seconds for TMT-A and 180 seconds for TMT-B, the tests' results were set to maximum time $[23,24]$.

\section{Gait measurements}

Gait characteristics were assessed by use of an electronic gait mat, GAITRite ${ }^{\circledR}$ mat (CIR systems Inc. Sparta, US), with a $4.88 \mathrm{~m}$ active area in the middle of an $8.0 \mathrm{~m}$ walkway. Participants walked the gait mat back and forth at an instructed preferred gait speed with their usual walking aids, if needed. If two walking trials were available, the mean value from the trials was calculated. Data were processed using the PKmas ${ }^{\circledR}$ software, where the mean and within-subject standard deviation (SD) of the steps within a walk, and the left/right ratio of spatial and temporal gait variables were calculated by the software. Gait speed is a robust measure of health and function [25]. In addition to gait speed $(\mathrm{m} / \mathrm{s})$, we used the following gait variables: step time (s), walk ratio (step length/cadence, where cadence is steps/minute), and the variability measure SD stride velocity $(\mathrm{cm} / \mathrm{sec})$, selected as potential metrics relevant for postural control during gait [26].

\section{Physical function measurements}

We used the Short Physical Performance Battery (SPPB) [27] as a measure of physical function. SPPB consists of three items, standing balance in three different positions, 4-meter walking, and five chair stands, and each item scored on a scale from 0 to 4 . The total score on SPPB ranges from 0 to 12 , with 12 the best score.

\section{Physical activity measurements}

We used small body worn accelerometers from PAL Technologies (Glasgow, UK) to monitor daily PA. The accelerometer was attached to the participants' right thigh and was measured acceleration continuously until removal of the sensor after one week. We included data from participants with a minimum of one day (24 hours) of complete recordings in the analyses. Mean time in upright position per day (Upright time) and mean number of sit-to-stand transitions per day (Upright events) were calculated from the data and used as outcome measures, along with information about the maximum length of the upright events (Max Event Length). The activity monitor and algorithms have been validated in a sample of older adults, showing valid measures of upright time and upright events [28]. Max Event Length is a more exploratory metric, but previously shown to be a predictor for outdoor mobility in hip fracture patients [29]. Multiple recording days for PA measures are recommended, however when comparing on a group level, one day of PA recordings has shown to be sufficient in a sample of hip fracture patients [30].

\section{Statistical Analysis}

The data are described as mean (SD) or percentages, as appropriate. Linear regression analyses were performed to examine the associations between dementia severity (CDR groups) and PA, physical function, and gait. Separate regression models were fitted for the dependent variables upright time, upright events, max event length, $\mathrm{SPPB}$, gait speed, step time, walk ratio, and stride velocity variability. The linear regression models included CDR group, age and their interaction as explanatory variables. Residuals were checked for normality by visual inspection of normal Q-Q-plots. The significance level was set to 0.05 . No formal adjustment of multiple testing was included. The results are presented as estimated mean differences with 95\% confidence intervals and p-values. All statistical analyses were performed using IBM SPSS 24 software (SPSS Inc., Chicago, IL, USA). 


\section{Results}

We included a total of 100 participants with age ranging from 64 to 93 years (57 women). In total, $60 \%$ of the 100 participants lived together with their spouse/others and $38 \%$ reported that they had assistance from municipal home care services. For our analysis, according to the CDR scores, $38 \%$ of the participants were classified as "no or questionable dementia" (group 1), 39\% as "mild dementia" (group 2), and $23 \%$ as "moderate to severe dementia" (group 3). Participant descriptive information is presented in Table 1.

The 88 participants fulfilling the criterion of at least 24 hours of complete recordings, wore the activity monitor for on average 4.2 days (SD 1.98), with a minimum of 48 hours for five participants. Participants spent on average 301 minutes per day in an upright position (standing and walking). Most of the participants walked without any walking aids (86\%), while 5\% walked with a roller, and $9 \%$ walked with one or two canes/crutches. There was no difference between groups in walking with or without walking aids during testing $(p=0.950)$. Mean gait speed was $0.93 \mathrm{~m} / \mathrm{sec}$. Descriptive information of participants' gait characteristics, physical function and PA is presented in Table 2.

The interaction effect between age and group was found not to be statistically significant in seven of eight linear regression models, with exception for gait speed $(p=0.021)$, therefore results from linear regression with main effects only are presented. After adjusting for age, there was evidence in the data, to different degrees, that cognitive function was associated with gait speed $(p=0.002)$, step time $(p=0.001)$, SPPB $(p=0.007)$, and upright time ( $p=0.031)$, see Table 3$)$. Overall, the "no or questionable dementia" group differed compared to the two other groups while here was little or no evidence in the data for differences between the mild versus the moderate to severe dementia groups. Those with "no or questionable dementia", as compared to those with mild dementia, had faster gait speed (mean difference 0.163 (95\% CI: 0.053 to 0.273$) p=0.004$ ), shorter step time $(-0.043(-0.082$ to -0.005$) p=0.029)$, higher SPPB score (1.7 (0.5 to 2.8) $p=0.005)$, and longer upright time (78.9 (18.9 to 139.0) $p=0.011)$. The "no or questionable dementia" group, as compared to those with moderate to severe dementia, had faster gait speeds $(0.208(0.076$ to 0.339$) p=0.002)$ and higher SPPB score (1.8 (0.5 to 3.2) $p=0.009$ ). The estimated mean differences for step time and upright time variables were slightly smaller when comparing the "no or questionable dementia" group to those with moderate to severe dementia, and the evidence of a difference was weaker, in such a way that the reduction in step time and increase in upright time were not statistically significant at the $5 \%$ level.

Table 1 Demographic and clinical characteristics, cognitive function of participants in the three groups

\begin{tabular}{|c|c|c|c|c|c|c|c|}
\hline \multirow[b]{2}{*}{ Characteristics } & \multicolumn{2}{|c|}{$\begin{array}{l}\text { No or questionable } \\
\text { dementia } \\
\text { Group } 1(n=38)\end{array}$} & \multicolumn{2}{|c|}{$\begin{array}{l}\text { Mild dementia } \\
\text { Group } 2(n=39)\end{array}$} & \multicolumn{2}{|c|}{$\begin{array}{l}\text { Moderate to severe } \\
\text { dementia } \\
\text { Group } 3(n=23)\end{array}$} & \multirow[t]{3}{*}{ Group differences } \\
\hline & & no. (\%) & & no. (\%) & & no. (\%) & \\
\hline Women & & $20(52.6)$ & & $24(61.5)$ & & $13(56.5)$ & \\
\hline Characteristics & n & Mean (SD, min-max) & $\mathbf{n}$ & Mean (SD, min-max) & $\mathbf{n}$ & Mean (SD, min-max) & $P$-values \\
\hline Age, years & 38 & $76.7(6.7,64-88)$ & 39 & $79.9(6.2,65-92)$ & 23 & $80.9(6.8,66-93)$ & 0.032 \\
\hline $\mathrm{BMI}$ & 32 & $25.4(4.4,16.3-33.1)$ & 32 & $25.4(3.9,19.4-34.8)$ & 22 & $24.9(3.9,17.5-32.2)$ & 0.885 \\
\hline Years of education & 36 & $11.1(3.4,7-21)$ & 39 & $10.5(3.1,7-22)$ & 22 & $9.8(3.1,7-17)$ & 0.364 \\
\hline IADL score, 0-8, women & 16 & $6.9(1.4,4-8)$ & 20 & $5.8(1.1,4-8)$ & 12 & $2.6(1.4,0-5)$ & $<0.001$ \\
\hline IADL score, 0-5, men & 16 & $4.1(0.8,3-5)$ & 14 & $3.3(1.1,1-5)$ & 8 & $2.3(0.7,1-3)$ & $<0.001$ \\
\hline Medications used on regular basis, no. & 36 & $4.5(2.6,0-11)$ & 35 & $4.7(3.1,0-12)$ & 23 & & 0.710 \\
\hline Grip strength, kg WOMEN & 16 & $21.6(8.9,12-49)$ & 19 & $18.2(4.0,9-25)$ & 9 & $16.0(4.4,8-20)$ & 0.086 \\
\hline Grip strength, kg, MEN & 14 & $35.7(9.4,24-56)$ & 9 & $26.4(7.0,18-42)$ & 9 & $29.2(8.2,20-42)$ & 0.039 \\
\hline MMSE, score, 0-30 & 36 & $25.0(4.1,10-30)$ & 34 & $21.9(4.2,15-30)$ & 23 & $17.0(3.9,10-25)$ & $<0.001$ \\
\hline CDT, score, 0-5 & 36 & $3.8(1.4,0-5)$ & 35 & $3.7(1.4,0-5)$ & 22 & $2.1(1.1,0-4)$ & $<0.001$ \\
\hline TMT-A time, sec ${ }^{\mathrm{a}}$ & 38 & $89.5(68.8,23-300)$ & 38 & $138.0(89.5,42-300)$ & 20 & $170.5(88.7,52-300)$ & 0.001 \\
\hline TMT-B time, sec ${ }^{b}$ & 34 & $164.2(32.7,48-180)$ & 32 & $170.9(22.0,105-180)$ & 12 & 180 & 0.173 \\
\hline
\end{tabular}

Groups are based on the CDR score where group 1 has a CDR score of 0 or 0.5 , group 2 has a CDR score of 1, and group 3 has a CDR score of 2 and 3; SD Standard Deviation, BMI Body Mass Index, IADL Instrumental Activities of Daily Living, MMSE Mini Mental State Examination, CDT Clock Drawing Test, TMT-A The Trail Making Test A, TMT-B The Trail Making Test B. ${ }^{a}$ For the TMT-A maximum second for test was set to 300 seconds; ${ }^{b}$ For the TMT-B maximum second for test was set to 180 seconds. The one-way analysis of variance (ANOVA) was used to indicate any statistically significant differences between the three groups. 
Table 2 Gait characteristics, physical function and physical activity of participants in the three groups

\begin{tabular}{|c|c|c|c|c|c|c|}
\hline \multirow[b]{2}{*}{ Characteristics: } & \multicolumn{2}{|c|}{$\begin{array}{l}\text { No or questionable dementia } \\
\text { Group } 1(n=38)\end{array}$} & \multicolumn{2}{|c|}{ Mild dementia Group $2(n=39)$} & \multicolumn{2}{|c|}{$\begin{array}{l}\text { Moderate to severe dementia } \\
\text { Group } 3(n=23)\end{array}$} \\
\hline & $\mathbf{n}$ & Mean (SD, min-max) & $\mathbf{n}$ & Mean (SD, min-max) & $\mathbf{n}$ & Mean (SD, min-max) \\
\hline \multicolumn{7}{|l|}{ Gait } \\
\hline Gait speed, m/s & 34 & $1.10(0.24,0.52-1.49)$ & 33 & $0.91(0.21,0.44-1.23)$ & 18 & $0.87(0.23,0.43-1.18)$ \\
\hline Step time, s & 34 & $0.58(0.7,0.45-0.78)$ & 33 & $0.61(0.1,0.51-0.95)$ & 18 & $0.62(0.9,0.49-0.83)$ \\
\hline Walk ratio, SL/Cad & 34 & $0.6(0.1,0.3-0.9)$ & 33 & $0.5(0.1,0.4-0.8)$ & 18 & $0.5(0.1,0.3-0.8)$ \\
\hline $\mathrm{SD}$ stride velocity, $\mathrm{cm} / \mathrm{s}$ & 34 & $3.86(1.2,2.10-7.22)$ & 33 & $4.13(1.4,2.01-6.96)$ & 18 & $4.0(0.94,2.45-5.83)$ \\
\hline \multicolumn{7}{|l|}{ Physical function } \\
\hline SPPB score, 0-12 & 35 & $10.4(2.1,5-12)$ & 37 & $8.3(2.7,3-12)$ & 20 & $8.1(2.8,3-12)$ \\
\hline \multicolumn{7}{|l|}{ Physical activity } \\
\hline Upright time, minutes & 35 & $345.7(97.3,148.9-637.4)$ & 35 & $265.7(125.6,95.3-572.2)$ & 18 & $282.4(160.7,74.1-648.1)$ \\
\hline Upright events, number & 35 & $48.8(15.5,26.3-92.0)$ & 35 & $45.9(16.5,23.2-91.0)$ & 18 & $45.2(12.7,26.3-70.0)$ \\
\hline Length of upright events, max & 35 & $83.6(38.6,28.4-213.0)$ & 35 & $68.3(47.2,14.0-228.2)$ & 18 & $67.0(36.6,11.4-129.2)$ \\
\hline
\end{tabular}

Groups are based on the CDR score where group 1 has a CDR score of 0 or 0.5 , group 2 has a CDR score of 1, and group 3 has a CDR score of 2 and 3; Physical activity was measured over a period of 2 to 7 days in this sample. SD Standard Deviation, SPPB The Short Physical Performance Battery

Table 3 Results from linear regression analyses for gait characteristics, physical function and physical activity, on cognitive function, adjusted for age

\begin{tabular}{|c|c|c|c|c|c|c|c|}
\hline \multirow[b]{2}{*}{ Characteristics } & \multicolumn{2}{|c|}{$\begin{array}{l}\text { No or questionable dementia vs. } \\
\text { Mild dementia } \\
\text { Group } 1 \text { vs. Group } 2\end{array}$} & \multicolumn{2}{|c|}{$\begin{array}{l}\text { No or questionable dementia vs. } \\
\text { Moderate to severe dementia } \\
\text { Group } 1 \text { vs. Group } 3\end{array}$} & \multicolumn{2}{|c|}{$\begin{array}{l}\text { Mild dementia vs. Moderate to } \\
\text { severe dementia } \\
\text { Group } 2 \text { vs Group } 3\end{array}$} & \multirow{2}{*}{$\begin{array}{l}\text { Overall } \\
\text { group } \\
\text { effect } \\
P \text {-value }\end{array}$} \\
\hline & $\begin{array}{l}\text { Mean difference }(95 \% \\
\mathrm{Cl})\end{array}$ & $P$-value & $\begin{array}{l}\text { Mean difference }(95 \% \\
\mathrm{Cl})\end{array}$ & $P$-value & $\begin{array}{l}\text { Mean difference }(95 \% \\
\mathrm{Cl})\end{array}$ & $P$-value & \\
\hline \multicolumn{8}{|l|}{ Gait } \\
\hline Gait speed (m/s) & 0.163 (0.053 to 0.273 ) & 0.004 & 0.208 (0.076 to 0.339$)$ & 0.002 & $0.045(-0.085$ to 0.174$)$ & 0.496 & 0.002 \\
\hline Step time (s) & $-0.043(-0.082$ to -0.005$)$ & 0.029 & $-0.035(-0.082$ to -0.011$)$ & 0.134 & 0.008 (-0.038 to 0.054$)$ & 0.730 & 0.001 \\
\hline Walk ratio, SL/Cad & $0.03(-0.01$ to 0.08$)$ & 0.149 & $0.05(-0.01$ to 0.10$)$ & 0.111 & $0.01(-0.04$ to 0.07$)$ & 0.696 & 0.198 \\
\hline $\begin{array}{l}\text { SD stride velocity } \\
(\mathrm{cm} / \mathrm{s})\end{array}$ & $-0.209(-0.819$ to 0.401$)$ & 0.497 & $-0.070(-0.795$ to 0.655$)$ & 0.848 & $-0.139(-0.578$ to 0.856$)$ & 0.701 & 0.788 \\
\hline \multicolumn{8}{|l|}{ Physical function } \\
\hline SPPB, score & 1.7 (0.5 to 2.8$)$ & 0.005 & $1.8(0.5$ to 3.2$)$ & 0.009 & $0.2(-1.1$ to 1.5$)$ & 0.783 & 0.007 \\
\hline \multicolumn{8}{|l|}{ Physical activity } \\
\hline Upright time, minutes & 78.9 (18.9 to 139.0) & 0.011 & $62.1(-10.6$ to 134.7$)$ & 0.093 & $-16.9(-88.5$ to 54.8$)$ & 0.641 & 0.031 \\
\hline $\begin{array}{l}\text { Upright events, } \\
\text { number }\end{array}$ & $1.6(-5.5$ to 8.7$)$ & 0.661 & 2.1 (-6.5 to 10.7$)$ & 0.632 & 0.5 (-8.0 to 9.0$)$ & 0.906 & 0.862 \\
\hline $\begin{array}{l}\text { Length of upright } \\
\text { events, max }\end{array}$ & $14.8(-5.5$ to 35.2$)$ & 0.151 & $16.0(12.4,-8.6$ to 40.7$)$ & 0.199 & $1.2(-23.1$ to 25.5$)$ & 0.922 & 0.271 \\
\hline
\end{tabular}

Groups are based on the CDR score, where score 0 and 0.5 are group 1, score 1 is group 2, and score 2 and 3 are group 3 . SPPB=The Short Physical Performance Battery. Physical activity was measured over a period of 2 to 7 days in this sample.

\section{Discussion}

We quantified gait characteristics, physical function, and daily-life PA, in home-dwelling, older people assessed at a geriatric memory clinic. The patients were grouped according to severity of their dementia. Participants in the "no or questionable dementia" group had better physical function (higher SPPB scores) compared to participants with mild dementia and moderate to severe dementia. The "no or questionable dementia" group also had faster gait speed and shorter step time, and they were more physically active with longer upright time, as compared to the groups with dementia, although the evidence was stronger when compared to the moderate to severe than to the mild dementia group.

As decline in physical function, including gait, is shown to precede decline in cognitive function [31, 32], the results for the "no or questionable" dementia group, especially for gait speed with an average value of $1.1 \mathrm{~m} /$ 
sec, was somewhat higher than expected. However, this group is very heterogenous with a range in gait speeds from 0.5 to $1.5 \mathrm{~m} / \mathrm{sec}$, where there would be different reasons for why persons have lower gait speeds in this group. The same was found for physical function as measured by the SPPB, with mean value of 10.4, and a range from 5 to 12 in the "no or questionable dementia" group.

Slowing of gait speed is a prominent change of gait, and could be a strategy when gait becomes more challenging [33]. Gait speed is suggested to be included as a minimum measure regarding motor and cognitive changes, and in contrast to for example SPPB, would only be challenged with ceilings effect in high functioning individuals [34]. Other gait characteristics or qualitative aspects of gait, such as those included in this study, might be more relevant in earlier phases to describe early decline in gait. One example is the study from Hausdorff et al. (2018), where declines both in quantity and quality of gait where seen among patients with MCI who had fallen [35]. Even subtask evaluations of specific measures of physical performance could be relevant, as some changes probably occur early and reflect changes that are not yet clinically significant [36]. Although more advanced or technological-dependent testing could be relevant for specific research questions, gait speed is easy to measure and thus easy to implement in clinical evaluations [34].

Our results indicate a difference in physical behavior including gait and physical function, between those having no or questionable dementia and the mild stages of dementia. Our findings are congruent with a study showing that dementia patients were more sedentary and performed less PA as compared to cognitively healthy controls [37]. There could be different causes for these findings such as brain pathology (neurodegeneration and vascular) and physical function, environmental factors related to lack of opportunities for PA due to increasing apathy [38, 39] and/or lack of caregiver support [40].

Traditionally we assess cognitive and physical impairment separately. An integrated approach could contribute to better understanding of both cognitive and motoric impairments [4, 7, 41]. Including daily-life measurements could further provide important insight into how PA and physical function are related to cognitive impairment [42]. Integrated approaches seem to be important, as among others the combination of gait problems and cognitive impairments could for example increase the overall risk of falling [43]. A study from Australia including persons with dementia indicated an association between daily-life PA and cognitive function [44]. It could be important to prevent decline in daily-life PA for this group, especially if a person experience challenges with participation due to their cognitive impairment. More clinical studies are needed, so we can guide development of PA interventions especially targeted for persons with dementia. Interestingly, our results for the no or questionable dementia group showed close to 30 minutes more in upright as compared to reference data for 75-79 years old, community-based individuals without dementia [45], and the mild dementia group showed close to 50 minutes less spent upright. For our moderate/ severe dementia group, with higher mean age, close to 30 minutes less time in upright was shown as compared to reference data for 80-84 years old individuals from the same sample [45]. In line with another recent study [11], strategies to improve healthy behaviors are needed, and we could speculate how to keep those with no or questionable dementia physically active as the potential to slower the a cognitive decline exist.

Acknowledging the increasing evidence for the associations between low levels of PA, sedentariness, and negative health outcomes [46], the follow-up of persons with dementia should include a focus on PA levels and physical functions. To be able to prevent decline in daily life functions, maintaining PA and physical function as long as possible is especially important for home-dwelling older adults [47]. With the increasing number of persons with age-associated dementia worldwide [48], and in the absence of a cure, healthcare professionals should ensure that people with dementia are encouraged to be physically active as this has the potential to delay functional decline [10]. Targeting high risk individuals for future dementia, with a focus on a dual decline in both memory and gait speed is suggested in recent studies $[49,50]$. An evaluation of individuals gait, physical function and PA in the no or questionable dementia group is thus highly relevant, confirming a potential and a need for a wider focus in memory clinics.

There are some important limitations with this study. First, this is a cross-sectional study from one memory clinic with a relatively low number of participants. Due to a modest number of participants, we were not able to perform more complex analyses. Data on comorbidities that may impact gait, physical function and physical activity were not available in our sample. We also speculate that selection bias is present for our group 3, moderate to severe dementia, as one inclusion criterion was being home-dwelling, and more persons in this severity of dementia group probably have been admitted to a nursing home. If we compare our sample with data from the NorCog registry, where our participants also were included, the cognitive status of our moderate/ severe dementia group could indicate that our clinic have included a more severe group of cognitive impaired individuals as compared to other memory clinics in Norway [51]. Our data provide the status at the time of diagnostic work-up. Although not being able to generalize, some 
important strengths should be highlighted. We included a relatively wide range of measures, including continuous registration of daily PA from body-worn sensors, performance-based measures of physical function and gait characteristics from gait-lab testing. The diagnostic evaluation was broad, ensuring important descriptive information of the sample included.

\section{Conclusion}

We found that less severe dementia was associated with better gait function, better physical function, and higher levels of PA, adjusted for age. Physical measures could provide complementary information to cognitive measures, both for gait, physical function and PA, and should be considered as part of assessments in cognitive evaluations for example in memory clinics. Further studies should assess how measures of gait, physical function, and PA as complementary measures for cognitive status could improve clinical evaluations when suspecting cognitive declines. We also need to know how these additional and complementary measures of cognitive status can be used to guide interventions. Finally, we need more knowledge on which or what combination of measures are most useful in clinical practice and for what reasons.

\section{Abbreviations \\ PA: Physical activity; CDR: Clinical dementia rating scale; SPPB: Short Physical Performance Battery.}

\section{Acknowledgements}

The GaitRite system was provided by NeXt Move, Norwegian University of Science and Technology (NTNU). NeXt Move is funded by the Faculty of Medicine at NTNU and Central Norway Regional Health Authority. We want to acknowledge the Norwegian register of persons assessed for cognitive symptoms (NorCog), for providing access to patient data.

\section{Authors' contributions}

IS, JLH, KT designed the study. KT performed the data collection in this trial in collaboration with the outpatient clinic. IS was responsible for the trial at the hospital and provided support during the trial. KT processed the data collected and performed the statistical analyses together with TF. KT and IS wrote the first draft of the manuscript. All authors read and approved the final manuscript.

\section{Funding}

This work was supported by the Norwegian Fund for Post-Graduate Training in Physiotherapy and the Liaison Committee between the Central Norway Regional Health Authority (RHA) and the Norwegian University of Science and Technology (NTNU). We thank the staff at the outpatient clinic at the Department of Geriatrics for collaboration during the work with the study trial.

\section{Availability of data and materials}

The datasets generated and analysed during the current study are not publicly available due to participant confidentiality

\section{Declarations}

\section{Competing interest}

The authors declare that they have no competing interests.

\section{Ethics approval and consent to participate}

The study was approved by the Norwegian Ethical Committee (2014/1689/ REK sør-øst A). Participants were eligible if they had agreed to take part in the Norwegian Register of Person assessed for Cognitive Symptoms (NorCog). We confirm that all participants consented for participation by use of written informed consent. The study was conducted following the Declaration of Helsinki.

\section{Consent for publication}

Not applicable.

\section{Author details}

${ }^{1}$ Department of Physiotherapy, Faculty of Health Sciences, Oslo Metropolitan University (OsloMet), Oslo, Norway. ${ }^{2}$ Department of Neuromedicine and Movement Science, Faculty of Medicine and Health Sciences, Norwegian University of Science and Technology (NTNU), Trondheim, Norway. ${ }^{3}$ Clinic of Clinical Service, St Olav University Hospital, Trondheim, Norway. ${ }^{4}$ Department of Clinical and Molecular Medicine, Faculty of Medicine and Health Sciences, Norwegian University of Science and Technology (NTNU), Trondheim, Norway. ${ }^{5}$ Research Centre for Age-related Functional Decline and Disease, Innlandet Hospital Trust, Ottestad, Norway. ${ }^{6}$ Norwegian National Advisory Unit on Ageing and Health, Vestfold Hospital Trust, Tønsberg, Norway. ${ }^{7}$ Department of Geriatric Medicine, Oslo University Hospital, Oslo, Norway. ${ }^{8}$ Faculty of Medicine, University of Oslo, Oslo, Norway. ${ }^{9}$ Department of Geriatrics, St Olav University Hospital, Trondheim, Norway.

Received: 22 June 2021 Accepted: 30 October 2021

Published online: 01 December 2021

\section{References}

1. Camicioli R, Howieson D, Oken B, Sexton G, Kaye J. Motor slowing precedes cognitive impairment in the oldest old. Neurology. 1998;50(5):1496-8.

2. Cohen JA, Verghese J, Zwerling JL. Cognition and gait in older people. Maturitas. 2016;93:73-7.

3. Kikkert LH, Vuillerme N, van Campen JP, Hortobagyi T, Lamoth CJ. Walking ability to predict future cognitive decline in old adults: A scoping review. Ageing Res Rev. 2016;27:1-14.

4. Verghese J, Annweiler C, Ayers E, Barzilai N, Beauchet O, Bennett DA, et al. Motoric cognitive risk syndrome: multicountry prevalence and dementia risk. Neurology. 2014;83(8):718-26.

5. Verghese J, Wang C, Lipton RB, Holtzer R. Motoric cognitive risk syndrome and the risk of dementia. J Gerontol A Biol Sci Med Sci. 2013;68(4):412-8.

6. Beauchet O, Annweiler C, Callisaya ML, De Cock AM, Helbostad JL, Kressig RW, et al. Poor Gait Performance and Prediction of Dementia: Results From a Meta-Analysis. J Am Med Dir Assoc. 2016;17(6):482-90.

7. Montero-Odasso M, Verghese J, Beauchet O, Hausdorff JM. Gait and cognition: a complementary approach to understanding brain function and the risk of falling. J Am Geriatr Soc. 2012;60(11):2127-36.

8. Erickson KI, Weinstein AM, Lopez OL. Physical activity, brain plasticity, and Alzheimer's disease. Arch Med Res. 2012;43(8):615-21.

9. Forbes D, Forbes SC, Blake CM, Thiessen EJ, Forbes S. Exercise programs for people with dementia. Cochrane Database Syst Rev. 2015;4:CD006489.

10. Laver K, Dyer S, Whitehead C, Clemson L, Crotty M. Interventions to delay functional decline in people with dementia: a systematic review of systematic reviews. BMJ open. 2016;6(4):e010767.

11. Desai P, Evans D, Dhana K, Aggarwal NT, Wilson RS, McAninch E, et al. Longitudinal Association of Total Tau Concentrations and Physical Activity With Cognitive Decline in a Population Sample. JAMA Netw Open. 2021;4(8):e2120398.

12. Braekhus A, Ulstein I, Wyller TB, Engedal K. The Memory Clinic--outpatient assessment when dementia is suspected. Tidsskr Nor Laegeforen. 2011;131(22):2254-7.

13. Lawton MP, Brody EM. Assessment of older people: self-maintaining and instrumental activities of daily living. Gerontologist. 1969;9(3):179-86.

14. Wattmo C, Wallin AK, Londos E, Minthon L. Risk factors for nursing home placement in Alzheimer's disease: a longitudinal study of cognition, ADL, 
service utilization, and cholinesterase inhibitor treatment. Gerontologist. 2011;51(1):17-27.

15. Ydstebo AE, Bergh S, Selbaek G, Benth JS, Luras H, Vossius C. The impact of dementia on the use of general practitioners among the elderly in Norway. Scand J Prim Health Care. 2015;33(3):199-205.

16. Hughes $C P$, Berg L, Danziger WL, Coben LA, Martin RL. A new clinical scale for the staging of dementia. Br J Psychiatry. 1982;140:566-72.

17. Folstein MF, Folstein SE, McHugh PR. "Mini-mental state". A practical method for grading the cognitive state of patients for the clinician. J Psychiatr Res. 1975;12(3):189-98.

18. Brodaty H, Moore CM. The Clock Drawing Test for dementia of the Alzheimer's type: A comparison of three scoring methods in a memory disorders clinic. Int J Geriatr Psychiatry. 1997;12(6):619-27.

19. Shulman KI. Clock-drawing: is it the ideal cognitive screening test? Int J Geriatr Psychiatry. 2000;15(6):548-61.

20. Reitan RM. Validity of the Trail Making test as an indicator of organic brain damage. Percept Mot Skills. 1958;8:271-6.

21. Spreen O, Strauss E. A compendium of neuropsychological tests. Administration, norms, and commentary, 2nd edn. New York: Oxford University Press; 1998.

22. Morris JC, Mohs RC, Rogers H, Fillenbaum G, Heyman A. Consortium to establish a registry for Alzheimer's disease (CERAD) clinical and neuropsychological assessment of Alzheimer's disease. Psychopharmacol Bull. 1988;24(4):641-52.

23. Munthe-Kaas R, Aam S, Ihle-Hansen H, Lydersen S, Knapskog AB, Wyller $T B$, et al. Impact of different methods defining post-stroke neurocognitive disorder: The Nor-COAST study. Alzheimers Dement (N Y). 2020;6(1):e12000.

24. Teuschl Y, Ihle-Hansen H, Matz K, Dachenhausen A, Ratajczak P, Tuomilehto J, et al. Multidomain intervention for the prevention of cognitive decline after stroke - a pooled patient-level data analysis. Eur J Neurol. 2018;25(9):1182-8.

25. Abellan van Kan G, Rolland Y, Andrieu S, Bauer J, Beauchet O, Bonnefoy $M$, et al. Gait speed at usual pace as a predictor of adverse outcomes in community-dwelling older people an International Academy on Nutrition and Aging (IANA) Task Force. J Nutr Health Aging. 2009;13(10):881-9.

26. Thingstad P, Egerton T, Ihlen EF, Taraldsen K, Moe-Nilssen R, Helbostad $J$. Identification of gait domains and key gait variables following hip fracture. BMC Geriatr. 2015;15:150.

27. Guralnik JM, Simonsick EM, Ferrucci L, Glynn RJ, Berkman LF, Blazer DG, et al. A short physical performance battery assessing lower extremity function: association with self-reported disability and prediction of mortality and nursing home admission. J Gerontol. 1994;49(2):M85-94

28. Taraldsen K, Askim T, Sletvold O, Einarsen EK, Gruner Bjastad K, Indredavik $B$, et al. Evaluation of a bodyworn sensor system to measure physical activity in older people with impaired function. Phys Ther. 2011;91(2):277-85.

29. Taraldsen K, Granat MH, Helbostad JL. Quantification of Outdoor Mobility by Use of Accelerometer-Measured Physical Behaviour. Biomed Res Int. 2015;2015.

30. Taraldsen K, Vereijken B, Thingstad P, Sletvold O, Helbostad JL. Multiple days of monitoring are needed to obtain a reliable estimate of physical activity in hip-fracture patients. J Aging Phys Act. 2014;22(2):173-7.

31. Verghese J, Wang C, Lipton RB, Holtzer R, Xue X. Quantitative gait dysfunction and risk of cognitive decline and dementia. J Neurol Neurosurg Psychiatry. 2007;78(9):929-35.

32. Hsu CL, Liang CK, Liao MC, Chou MY, Lin YT. Slow gait speed as a predictor of 1-year cognitive decline in a veterans' retirement community in southern Taiwan. Geriatr Gerontol Int. 2017;17(Suppl 1):14-9.

33. Ijmker T, Lamoth CJ. Gait and cognition: the relationship between gait stability and variability with executive function in persons with and without dementia. Gait Posture. 2012;35(1):126-30

34. Montero-Odasso M, Almeida QJ, Bherer L, Burhan AM, Camicioli R, Doyon J, et al. Consensus on Shared Measures of Mobility and Cognition: From the Canadian Consortium on Neurodegeneration in Aging (CCNA). J Gerontol A Biol Sci Med Sci. 2019;74(6):897-909.

35. Hausdorff JM, Hillel I, Shustak S, Del Din S, Bekkers EMJ, Pelosin E, et al. Everyday Stepping Quantity and Quality Among Older Adult Fallers With and Without Mild Cognitive Impairment: Initial Evidence for New Motor Markers of Cognitive Deficits? J Gerontol A Biol Sci Med Sci. 2018;73(8):1078-82.
36. Mirelman A, Weiss A, Buchman AS, Bennett DA, Giladi N, Hausdorff JM. Association between performance on timed up and go subtasks and mild cognitive impairment: Further insights into the links between cognitive and motor function. J Am Geriatr Soc. 2014;62(4):673-8.

37. Hartman YAW, Karssemeijer EGA, van Diepen LAM, Olde Rikkert MGM, Thijssen DHJ. Dementia Patients Are More Sedentary and Less Physically Active than Age- and Sex-Matched Cognitively Healthy Older Adults. Dement Geriatr Cogn Disord. 2018;46(1-2):81-9.

38. Brodaty $\mathrm{H}$, Burns $\mathrm{K}$. Nonpharmacological management of apathy in dementia: a systematic review. Am J Geriatr Psychiatry. 2012;20(7):549-64.

39. Brodaty H, Connors MH, Xu J, Woodward M, Ames D, group Ps. The course of neuropsychiatric symptoms in dementia: a 3-year longitudinal study. Journal of the American Medical Directors Association. 2015;16(5):380-7.

40. Granbo R, Boulton E, Saltvedt I, Helbostad JL, Taraldsen K. My husband is not ill; he has memory loss - caregivers perspectives on health care services for persons with dementia. BMC Geriatr. 2019;19(1):75.

41. Kueper JK, Speechley M, Lingum NR, Montero-Odasso M. Motor function and incident dementia: a systematic review and meta-analysis. Age Ageing. 2017:46(5):729-38.

42. Taylor ME, Boripuntakul S, Toson B, Close JCT, Lord SR, Kochan NA, et al. The role of cognitive function and physical activity in physical decline in older adults across the cognitive spectrum. Aging \& mental health. 2019;23(7):863-71.

43. Martin KL, Blizzard L, Srikanth VK, Wood A, Thomson R, Sanders LM, et al. Cognitive function modifies the effect of physiological function on the risk of multiple falls-a population-based study. J Gerontol A Biol Sci Med Sci. 2013;68(9):1091-7.

44. Taylor ME, Brodie MA, van Schooten KS, Delbaere K, Close JCT, Payne N, et al. Older People with Dementia Have Reduced Daily-Life Activity and Impaired Daily-Life Gait When Compared to Age-Sex Matched Controls. Journal of Alzheimer's disease : JAD. 2019.

45. Rosenberg D, Walker R, Greenwood-Hickman MA, Bellettiere J, Xiang Y, Richmire K, et al. Device-assessed physical activity and sedentary behavior in a community-based cohort of older adults. BMC Public Health. 2020;20(1):1256.

46. Ekelund U, Tarp J, Steene-Johannessen J, Hansen BH, Jefferis B, Fagerland $\mathrm{MW}$, et al. Dose-response associations between accelerometry measured physical activity and sedentary time and all cause mortality: systematic review and harmonised meta-analysis. BMJ. 2019;366.

47. Lewis $\mathrm{M}$, Peiris CL, Shields N. Long-term home and community-based exercise programs improve function in community-dwelling older people with cognitive impairment: a systematic review. J Physiother. 2017;63(1):23-9.

48. Prince M, Bryce R, Albanese E, Wimo A, Ribeiro W, Ferri CP. The global prevalence of dementia: a systematic review and metaanalysis. Alzheimer's \& dementia : the journal of the Alzheimer's Association. 2013;9(1):63-75 e2.

49. Tian Q, Resnick SM, Mielke MM, Yaffe K, Launer LJ, Jonsson PV, et al. Association of Dual Decline in Memory and Gait Speed With Risk for Dementia Among Adults Older Than 60 Years: A Multicohort Individual-Level Metaanalysis. JAMA Netw Open. 2020;3(2):e1921636.

50. Tian Q, Studenski SA, Montero-Odasso M, Davatzikos C, Resnick SM, Ferrucci L. Cognitive and neuroimaging profiles of older adults with dual decline in memory and gait speed. Neurobiol Aging. 2021;97:49-55.

51. Nåvik MB BH, Kirkevold ET, Bergh S, Selbæk G. The Norwegian registry for persons assessed for cognitive symptoms (NorCog) - Årsrapport for 2019 med plan for forbedringstiltak. https://www.kvalitetsregistre.no; 2020 30.09.2020.

\section{Publisher's Note}

Springer Nature remains neutral with regard to jurisdictional claims in published maps and institutional affiliations. 